\title{
Summing up the Sentences in Active Voice without Passive Counterparts
}

\author{
Yanying Xu \\ Foreign Language School, Changchun University of Science and Technology, 7989 Wei Xing Road, Changchun, China \\ Email: xuyanying0864@163.com
}

\begin{abstract}
Some active English sentences can express passive implicature and they have no passive counterparts. In what cases can't they convert into passive voice (or have no passive counterparts)? The paper will make a study on the problem from four various cases of active sentences without passive counterparts. By analyzing the four cases, the author draws a conclusion that the variety in English voice shows the tendency of the linguistic phenomenon of active voice taking the place of passivisation.
\end{abstract}

Index Terms - active voice, passive voice, passive counterparts

\section{INTRODUCTION}

In English, only sentences with a transitive verb can be turned into passive ones. However, not all English transitive sentences have passive counterparts. Some of them and some intransitive ones can also indicate passive implicature. So the passive counterparts are unnecessary for them. In the following cases, passive construction is neither allowed nor unusual.

\section{VARIOUs CASES OF ACtive Sentences Without PASSIVE COUNTERPARTS}

The passive implicature of English sentences can be expressed in different way. Not all the passive indication must be expressed with the sentence in passive voice. Some active voice sentences themselves imply passive implication. Some transitive verbs, for example, do not occur in the passive. Intransitive verbs never appear in the passive construction. But, in some cases, these transitive verbs or intransitive ones also indicate the sense of passivization.

\section{A. Transitive Verb Performed as Predicate in a Sentence}

Transitive verbs with reflexive or reciprocal objects do not passivize, for instance,

1) He had busied himself in the laboratory.

2) Conrad and I contented ourselves with expressing our relief.

3) He prides himself on his tidiness.

4) Don't deceive yourself.

We could not substitute any other NP (Noun Phrase) for the reflexives, and there are, accordingly, no passive counterparts. Where a reflexive is in paradigmatic opposition to other NPs, as in "John enjoyed himself", not* "Himself was enjoyed by John", for the reflexive must follow its antecedent.

If the object is "each other" or "one another", for both of them are accusatives and reciprocal, the active voice has no passive counterparts as in the following two examples:

1) a. They helped each other.

*b. Each other was helped.

2) a. They loved one another.

*b. One another was loved.

We cannot passivize sentences like "Patrick liked/wanted/hated Mary to accompany him." as in "*Mary was liked/wanted/hate to accompany him." The reason is not clear. Some grammarians think that this is because the constituent structure of the active is unclear, so that it is arguable whether "Mary" is in fact an object. However, we can certainly passivize sentences such as "Patrick expected Mary to accompany him" and "Patrick believed Mary to be right", which are of the same structures.

Where a verb has a sense in which it is logically symmetrical, passivisation is unlikely or excluded even for some speakers. For example, "marry" in the sense "enter into matrimony with" is logically symmetrical in that "X married Y" entails and is entailed by "Y married X"; the same can be said about resemble and equal. Thus, examples like "Tom was married/resembled by Lucy" and "A is equaled by B" are judged awkward or unacceptable.

And some "verb+noun" combinations, which have the force of an intransitive verb, can never take the passive. For example,

The medicine soon took effect. The plant will soon take root.

In the above two sentences, effect and root are nouns and seemingly function as the objects of took and take 
respectively. But, take effect and take root are actually phrasal verbs to indicate the sense of work and put down. This kind of forms is mostly treated as single-word verb and they are intransitive verbal phrases. They certainly take no passive counterparts.

Some stative verbs, though transitive, do not occur in the passive, for example,

The plane holds about 150 people. These students lacked experience.

The transitive verbs holds and lacked are followed by objects but about 150 people and experience are not the recipients of actions because holds and lacked are stative verbs referring to states but not actions. Stative verbs are normally incompatible with the passive voice except in certain cases where there is a transfer of meaning. Only the dynamic verbs refer to actions and occur in passive voice commonly.

Some verbs followed by a gerund, the active form of the kind of verbs implicate the passive meaning. In modern English, there're only few verbs, such as bear, deserve, need, require, want etc in the following sentences. So the passive counterpart is unacceptable as well in the following examples:

a) Polyester bears washing.

b) She deserves praising.

c) The best horse needs braising and the aptest child needs teaching.

d) Charles Berford will require looking after one of those days.

e) These boxes want numbering.

There are some verbs that can be either transitive or intransitive in the present progressive and express the passive meaning as remnants of Old English. We will mention it in the third section, later.

\section{B. Intransitive Verb Performing as the Predicate in a Sentence}

If some intransitive verbs such as move, lock, shut, open are used in negative sentences, they show the meaning of "impossibility" with conversational implicature in passive voice. Look at the following examples:

1) The door won't shut.

2) The window won't open.

3) The car won't move.

4) The bread doesn't bake well in the oven.

5) Dogs don't drown easily.

6) This cake doesn't break evenly.

The above examples are in active form but in passive meaning. So they are unnecessarily expressed in passive form semantically and syntactically they are ungrammatical if they are transferred into passive voice.

Some actional active intransitive verbs like rise, lie, happen, occur, live, etc can not be followed by an object, so they have no passive counterparts. For instance

1. He rose to welcome us (stood up).

2. The lazy man lay in bed until noon (stayed).

3. What he said would happen really happened (came to pass/took place).

4. Did you see what was happening (passing).

5. When did the accident occur (take place)?

6. We couldn't live without food and water.

Some intransitive verbs, such as wear and blow can be used in "subject + predicate + subjective complement". This kind of active sentence cannot be transferred into passive pattern. Such as:

1) This material has worn thin.

*This material has been worn thin.

2) The door blew open.

* The door was blown open.

\section{The Predicate in a Sentence with the Verb Both Performing as Transitive \& Intransitive}

Some statal active verbs, which can be used as both transitive \& intransitive, have no passive counterparts. Such kind of verbs include have (means owning), lack (means be insufficient), resemble (means be similar to) as in the following sentences:

1) a. John has a new car.

* A new car is had by John.

2) a. Dick lacks courage and intelligence.

* Courage and intelligence are lacked by Dick.

3) a. Tom resembles his father in character.

* Tom's father is resembled by Tom in character.

There are verbs that can be either transitive or intransitive and which can be active in form but passive in meaning. The following two points may be noted. The first of these which occurs chiefly in the present progressive, if found in some of the daily expressions and professional jargons known as remnants of Old English, for example:

The house is building. The book is printing. The dinner is cooking.

Verbs used in this way can also be made passive. Let's compare the following progressive passive version with the 
above sentences:

The house is being built. The book is being printed. The dinner is being cooked.

The second version occurring frequently in the simple present is only found when the subject is represented as having certain inherent qualities which promote, hamper, or prevent the realization of the idea expressed by the predicate verb, for example:

Tomatoes bruise easily. $\quad$ My voice doesn't carry well. $\quad$ Nylon dries quickly. The door won't lock.

By the side of the active constructions under the discussion there exist corresponding passive, but they have a demonstrably different meaning. For example:

His novels don't sell. $\longleftrightarrow$ His novels are not sold.

When we say the sentence in the previous pattern, we suggest that they have certain inherent qualities which prevent or adversely affect their sale, that they definitely do not belong to the category of best-sellers or quality; when we say that in the latter pattern, we make a mere statement of fact about them.

Some transitive verbs in English have a tendency of intransitivity. When patient is in the nominative position, the transitive verb is used as intransitive one, and the actor is not concerned. The verbs are usually followed by some gradable or statal adverbs like well, nicely, easily, smoothly. Some common intransitive verbs like these are read, write, wash, clean, draw, burn, cook, photograph, etc, as in the following sentences:

1) The cloth washes well.

*The cloth is washed well.

2) The book sells well.

* The book is sold well.

3) The poem reads smoothly.

* The poem is read smoothly.

4) The ball rolls nicely

* The ball is rolled nicely.

5) The cistern doesn't clean easily.

* The cistern isn't cleaned easily.

6) The orange peels easily.

*The orange is peeled easily.

7) This kind of rice cooks more quickly than that kind.

* This kind of rice is cooked more quickly than that kind.

8) The pen writes smoothly.

* The pen is written smoothly.

9) I always photograph well.

*I am always photographed well.

This kind of intransitivity can express the property of the patient, but not the action of it. So it shows statal activity, and has no passive counterpart.

\section{Some Other Special Cases}

In the locative adverbial containing a preposition and a locative noun, the locative noun (functioning as the object of the preposition) can not perform as the subject in a sentence, so the sentence in active voice cannot be transferred into passive one, for instance:

1) a. He has traveled in America.

*America has been traveled in by him.

2) a. She has never walked in the street.

* The street has never been walked in by her.

3) a. The piano won't go through the narrow entrance.

* The narrow entrance won't be gone through by the piano.

As for some link verbs, such as smell, taste, sound, prove, feel, seem, look, remain, etc, the active form of them can express the passive meaning, so passive counterparts are unnecessary. For example:

1) The flowers smell sweet.

2) That sounds very reasonable.

3)The story proved quite false.

\section{CONCLUSION}

Language always develops with society. We usually search for the simplest way to express what we mean. The variety in English voice shows the tendency to be simpler. The active voice will take place some passivisation. This kind of linguistic phenomenon is sure to become usual with the development of English. So, a new topic on linguistic study is how to search for the objective rules for the peculiar kind of linguistic phenomenon. All the cases mentioned above are just a part of it. Maybe, they will draw much more attention of English learners and stimulate them to study it in detail. 


\section{REFERENCES}

[1] Andrew Radford. (2000). Transformational Grammar: A First Course. Beijing: Foreign Language and Research Press \& Cambridge University Press.

[2] Bao Bing. (2004). A Hand Book of English Grammar. Beijing: The Commercial Press.

[3] John Sinclair. (1999). Collins Cobuild English Grammar Course Book. Beijing: The Commercial Press.

[4] Wang Fengxin. (1998). A Notional Grammar of English (Revised Version). Beijing: Foreign Language Press.

[5] Xin Bin. (1995). The Basic Theory of Grammar. Changchun: Ji Lin University Press.

[6] Zhang Zhenbang. (2009). A New English Grammar Coursebook. Shanghai: Shanghai Foreign Language Education Press.

[7] Zhu Yongsheng. (2003). A Survey of Systemic-Functional Grammar. Wuhan: Hunan Educational Press.

Yanying Xu was born in Tonghua, Jilin, China in 1968. She received her M.A degree in foreign linguistics and applied linguistics from Changchun University of Science and Technology, China in 2004.

She is currently an associate professor and vice dean in the School of Foreign Languages, Changchun University of Science and Technology, Changchun, China. Her research interests include Stylistics, Grammar, Translation and Academic Paper Writing. 